\title{
Literature Review on Adaptation of Fixed Prosthesis Metal Infrastructure
}

\author{
Éber Coelho Paraguassu1, Ulisses Gomes Guimarães Neto ${ }^{2}$, Alan Mesquita dos Santos ${ }^{3}$, \\ Carolina Pantoja Calandrine de Azevedo ${ }^{3}$, André Fabricio da Costa Oliveir ${ }^{2}$, Karina da Silva \\ Figueira $^{1}$
}

${ }^{1}$ Department of Odontological Sciences , GOE/ UNIAVAN, Macapá, Amapá, Brazil, ${ }^{2}$ Department of Odontological Sciences, Faculdade de Macapá, Macapá, Amapá, Brazil, ${ }^{3}$ Department of Odontological Sciences, IMMES, Macapá, Amapá, Brazil

\begin{abstract}
This article aims to carry out a systematic review of the current medical literature on the adaptation of structures of prostheses on prefabricated implants or melted in titanium, before and after laser welding. It was used as methodology a scan was carried out on the main indexing platforms for scientific articles. We found 40 articles on the subject; however, 24 had a low impact factor or index on the Qualis platform below B2 and were discharged. According to the method employed and based on the results obtained in the literature for the two techniques studied, it was concluded that the monoblock technique is safer than the distal bar technique since this technique promotes less or no distortion which would promote stresses on the implants.
\end{abstract}

Key Words: Prostheses, Laser welding, Dental implants

\section{Introduction}

Since the introduction of the concept of osseointegration in 1983 [1] there has been increasing use and evolution of osseointegrated implants, making them effective in solving a wide range of clinical cases, there is still a search for surgical and prosthetic protocols with the intention of reducing time and cost of treatment to the patient.

As in conventional prostheses, implant prostheses need infrastructures that show perfect adaptation, but in the meantime no metallic dental infrastructure was perfectly suited to the prepared tooth and the complete adaptation was very variable due to the various procedures that preceded its preparation, making possible an absolute nonexistent adaptation of 100 to $150 \mu \mathrm{m}$ of clinically acceptable maladaptations [2]. Thus, it is possible to assume that the failure of the infrastructures arises from the various clinical and laboratory stages to which any prosthetic part is submitted [3].

The total of edentulous patients, in most cases, presents problems related to the amount of bone tissue posterior to the mental foramen, causing the implants to be positioned in the region between the foramina, a fact that leads to the use of prostheses with extensions in cantilever. The literature reports that the cantilever distance can vary from 10 to $20 \mathrm{~mm}$, allowing placement of up to two teeth in this region [4].

The most frequent mechanical failures in implant prostheses are the loosening and fracture of the prosthesis screws and the intermediate pillar, acrylic and bar fracture in the weld area [5].

However, defects resulting from the casting process, such as distortions, directly influence the adaptation and resistance of rods when made in monoblock, laser welded or TIG (Tungsten inert gas) or further segmented brazing [6].

The present work will analyze a systematic review of the current medical literature on the fatigue resistance of cantilevers in Branemark protocol type implants, made in two different ways: a cemented monoblock bar and a distal bar through a fatigue test.

\section{Methodology}

A systematic review of the medical literature in the Pubmed, Sciello, Capes Periodicals and Web Sciences indexing portals was carried out. We found 40 articles on the adaptation of denture structures to prefabricated or cast-in-titanium implants, before and after laser welding, however, 24 had a low impact factor or index on the Qualis platform below B2 and were excluded. The 16 articles selected were reviewed and summarized in the form of a systematic review.

\section{Systematic Review}

A study carried out to evaluate the adaptation of a fixed prosthesis of three elements in the teeth, objectively the relative distortion in three unitary bridges joined by laser welding, brazing, monoblock. The results obtained were 35.2 $\mu \mathrm{m} ; 49.1 \mu \mathrm{m} ; 202.7 \mu \mathrm{m}$; Laser welding; monobloc and brazing $\mathrm{Co}-\mathrm{C}$. The values found for laser and monobloc welding were significantly higher than brazing [7].

The development of the so-called Cresco $\mathrm{Ti}$ technique, which makes it possible to correct and reduce the mismatch of infill structures in monoblock, where after the casting of the monoblock it is adapted in the analogs of the respective molding, then a fixation is made on the infrastructure so that the structure can be sectioned between the melting of the prefabricated prosthetic components and the bar itself, thereafter the components are screwed into the index and laser welded with the prosthetic components. The technique does not allow correction of incorrect moldings, if this occurs, only a new impression can solve this problem [8].

An article verified the distribution of stress in fixed implants components supported by the use of strain gauges, as a function of their Cobalt-Chromium ( $\mathrm{Co}-\mathrm{Cr}$ ) and PalladiumSilver (Pd-Ag) alloys. The bars were designed simulating prosthesis bars, where a vertical static load of $100 \mathrm{~N}$ was applied at the free end, at a distance of 10, 15 and $20 \mathrm{~mm}$ distal from the center of the terminal intermediate. After the tests, the results showed that in large extensions of the cantilever, the cobalt-chromium alloy presented a pattern of 
force distribution similar to the palladium-silver alloy with short cantilever. Regardless of the place of application of the force and the alloy used in the construction of the infrastructures, the intermediate closest to the point of application of the load was the one that recorded the highest specific deformation. The use of a cobalt-chromium alloy in the fabrication of implanted implant infrastructures may allow more extensive cantilever arms since its modulus of elasticity is greater than the palladium-silver alloy provided a better distribution of forces mesial and distal regions [9].

Investigations on the effects of clinical variables on the length of cantilevers were evaluated in a clinical study. The variables studied were number and distribution of the implants, with the optimal length of the cantilevers for each situation and the anteroposterior distance of the implants (anterior implant and posterior implant). The locations of implants and prostheses were made from 55 clinical cases and transferred to models. Using the Skalak model, a load of 143 $\mathrm{N}$ was calculated and applied vertically to the implants in more than 500 places. The results showed that: when using eight implants with cantilevers of up to $36 \mathrm{~mm}$ there were no complications; related cantilever length at $20 \mathrm{~mm}$ with six and five implants the results showed complications in 33\% and 93\% of the cases for six and five implants respectively; using cantilevers of $15 \mathrm{~mm}$ the complications for 6,5 and four implants were of $22 \%, 53 \%$, and $92 \%$ respectively; for $12 \mathrm{~mm}$ of cantilever length with 6,5 and four implants the complications were $11 \%, 40 \%$ and $85 \%$; and finally to $10 \mathrm{~mm}$ length in cases of 6,5 , and 4 implants the complications were $0 \%, 20 \%$, and $85 \%$. The best model for $10 \mathrm{~mm}$ cantilevers is one that has a number of implants greater than four. Success rates were $100 \%, 56 \%, 33 \%, 8 \%$ and $0 \%$ for cases, supported by eight and seven, six, five, four, and three implants respectively [10].

The evaluation of the passive settlement of implantedimplant fixed prosthesis infrastructures, made by the cemented and laser-welded cylinder techniques were reported in the literature. A master model was fabricated from an edentulous mandible in chrome steel where five analogs of aesthetic pillars were fixed. Master models were obtained in type $\mathrm{V}$ gypsum (Exadur ${ }^{\circledR}$-Polydental). On the models, where the analogs were incorporated, the waxing procedures were performed, 20 metallic structures cast in commercially pure titanium (Tritan ${ }^{\circledR}$-Dentaurum-Pforzheim-Germany), divided into two groups, where internal reliefs were made in the structures, which allowed the adaptation of the titanium cylinders (111-CNB-Connection Systems of Prostheses). In the group of welded cylinders, these were fixed with acrylic resin (Duralay ${ }^{\circledR}$ ) and later laser welded. In the group of cemented cylinders, only the central cylinder was laser welded, and the others cemented with resin cement (Panavia $\mathrm{F}^{\circledR}$-Kuraray Co.). Measurements were performed with the aid of a measuring microscope (STM Digital-Olympus-Japan), with an accuracy of $0.0005 \mathrm{~mm}$. The results were submitted to analysis of variance (ANOVA) and to the statistical test $\mathrm{F}$, at a level of $5 \%$ of probability, demonstrating that for the central position, the passive settlement was better for the "cemented" group $\pm 12.54 \mu \mathrm{m})$ in relation to the "welded" group (99.06 \pm $50.47 \mu \mathrm{m}), \mathrm{p}<0.05$. Similarly, in relation to the distal position, the mean misalignment was lower for the "cemented" group
$(29.17 \pm 16.160)$ than the "welded" group $(70.21 \pm 56.70 \mu \mathrm{m})$, $\mathrm{p}<0.05$. The technique of the cemented cylinders was the one that presented better results of passive laying [11].

The evaluation of the adaptation of the prosthetic component interface (UCLA)/implant, through three different techniques was reported in a clinical study: laser welding (group 1), monobloc casting (group 2) and casting and laser welding (group 3). Each structure had three prosthetic components connected by two bars. Each group had 10 specimens. In group one the prefabricated structures were used, being they only welded to the laser. In group two the calcinable structures were waxed and monobloc cast. Group two was later sectioned and renamed group three, then laser welded. All groups were measured in a microscope with the precision of $0.0005 \mathrm{~mm}$ in relation to the adaptation, before and after the procedures to obtain the structures, through each technique. The results showed that group 1 presented a statistically superior adaptation, initial $(0.000 \mu \mathrm{m})$ and final $(9,931 \mu \mathrm{m})$, in relation to groups $2(9,568 \mu \mathrm{m}$ and 101,722 $\mu \mathrm{m})$ and $3(20,258 \mu \mathrm{m}$ and $31,440 \mu \mathrm{m})$. Group three showed a significant improvement over group two. The technique with better adaptation was the one that used pre-fabricated components only laser welded [12].

One study evaluated the passive laying of implantsupported fixed prosthesis infrastructures, using UCLA and aesthetic abutments, monobloc cast or laser welding, before and after electroerosion, through the analysis of marginal discrepancies. Forty infrastructures were made from a master metal model with five implants and cast in commercially pure titanium. The samples were divided into eight groups: G1-10 monobloc fused structures with UCLA pillar, G1+EDM, G2-10 molten structures with UCLA pillar and sectioned at 4 points and subjected to laser welding, G2+EDM, G3-10 structures G4+EDM, G4-10 molten structures with antistatic pillar and sectioned at 4 points and submitted to laser welding, G4+EDM. The different degrees of marginal adaptation between abutment type UCLA/implant and abutment/ aesthetic/infrastructure were evaluated before and after electroerosion, assessing the marginal discrepancies in the implant (IC) and in the distal (ID), using an optical microscope with the precision of $0.0005 \mathrm{~mm}$. After tabulation of the data, the results were submitted to the non-parametric Mann-Whitney test. The author can conclude that group 1 (monobloc pieces), obtained the worst marginal adaptation, and UCLA pillar provided foundries with a better degree of marginal adaptation than the esthetic pillar. G1+EDM and G2 and G3+EDM and G4 [13].

In an evaluation, analysis and comparison of samples made of commercially pure titanium and Ti-6AL-4V alloy intact and laser welded in a fatigue-corrosion test where 60 different samples were tested in a different storage medium. Dumbbells with $2.3 \mathrm{~mm}$ diameter in the central segment were obtained from the Rematitan casting system. Fatigue-corrosion tests were performed with a load $30 \%$ below the flow limit at $0.2 \%$ of the displacement, three storage situations were combined: without immersion, with artificial salivary and with fluoridated artificial saliva. After a fracture, the number of cycles was recorded and the fracture interface analyzed in SEM. The fractured samples were laser welded, machined and retested under the same conditions as intact samples. ANOVA 
and Tukey's test was used for the statistical test, being $\mathrm{p}<0.05$. The results showed a reduction in the number of cycles of the fracture, being 5674-artificial saliva and 3948 cycles fluoridated saliva and 16186 cycles without the means, for samples tested in the presence of the storage solutions, with a statistically significant difference in relation to the samples tested. The laser welding process influenced negatively, reducing the number of cycles until the fracture (6146 cycles), showing statistically significant differences in relation to the intact samples (11060). Within the limitations of this study, the number of cycles for fracture decreased in environments with storage media and the laser welding process negatively influenced the life of the metals when subjected to the fatiguecorrosion tests [14].

In a search to evaluate the flexural strength of distal bars that make up the Brånemark Novum ${ }^{\circledR}$ System's prosthetic structure, varying the type of welding used: LASER and TIG, and the diameter of the implants, 12 implant-supported titanium infrastructures, each with two distal bars and three implants, the arrangement of which follows the protocol of the Brånemark Novum ${ }^{\circledR}$ system. The infrastructures were divided into four groups $(n=6)$, with different types of welding and different diameters of the prosthetic components. The six structures of the Regular Group were divided into three laserwelded infrastructures (GRL) and three infrastructures welded by the TIG system (GRT). The same division is repeated with the six of Largo Group (GLL and GLT). These structures were submitted to vertical force at their extremity by means of the EMIC DL 2000 machine. The values obtained in the test were used in the formula to obtain the flexural stress (MPa) in circular section bodies. The data obtained after the use of the equation were treated by means of statistical analysis of Variance-(ANOVA), where they did not present significant statistical difference for the four analyzed groups, for the two factors of variation analyzed: Type of weld and diameter of the pillars, with significance index of $(\mathrm{p}<0.05)$ [15].

This in vitro research was aimed to compare the impact of distal cantilever extension on the stress around four implants retained palateless overdenture by means of a bar. Four implants were placed bilaterally in lateral incisor and the first premolar positions of edentulous acrylic resin maxillary model; connected bar with $7 \mathrm{~mm}$ distal cantilever extension with soft liner female retentive element was used. Eight strain gauges were bonded to the acrylic resin at the mesial and distal surfaces of each implant, stress was measured, then the $7 \mathrm{~mm}$ cantilever extension was trimmed and the stress measured for the bar without distal cantilever extension. Bar with distal cantilever extension demonstrates a significant increase in stress compared to the bar without distal cantilever extension in unilateral loading and bilateral loading. During unilateral loading in a bar with distal cantilever extension and bar without distal cantilever extension, the maximum stress was recorded at the mesial side of the posterior implant of loading side. The four implants connected with the bar without distal cantilever extension demonstrates lower stress than a bar with distal cantilever extension [16].

\section{Conclusion}

According to the method used for the two techniques studied, it was concluded that the monoblock technique is safer than the distal bar technique because it promotes minor or no distortion, which would promote stresses in the implants. The initial marginal adaptation of the technique with prefabricated components in Ti c.p. and laser-welded is statistically superior to monobloc casting and casting plus laser welding techniques; Laser welded bars are better suited than monobloc cast bars.

\section{References}

1. Brånemark R, Brånemark PI, Rydevik Björn, Myers RR. Osseointegration in skeletal reconstruction and rehabilitation: A review. Journal of Rehabilitation Research and Development. 2001; 38: $175-181$.

2. Gomes EA, Assunção WG, Costa PS, Delben JA, Barão VAR, et al. Aspectos clínicos relevantes no planejamento cirúrgico protético em implantodontia. Journal of Human Sciences. 2008; 27 : 111-124.

3. Eames WB, Macnamara JF. Evaluation of casting machines for the ability to cast sharp margins. Operative Dentistry. 1978; 3: 137-141.

4. Santos LB, Corazza TMVF, Sampaio NM, Oliveira AS. Aspectos biomecânicos das próteses sobre implantes odontologia. Odontologia Clínico Científica. 2007; 6: 13-18.

5. Pedrazini MC, Wassall T. Falhas de fundição nas infraestruturas de próteses ferulizadas sobre implantes: ensino in vitro 1. $R G O$. 2009; 57: 165-172.

6. Misch CM. Immediate loading of definitive implants in the edentulous mandible using a fixed provisional prosthesis: the denture conversion technique. Journal of Oral and Maxillofacial Surgery. 2004; 62: 106-115.

7. Hulyng JS, Clark RE. Comparative distortion in three-unit fixed prostheses joined by laser welding, conventional soldering, or casting in one piece. Journal of Dental Research. 1977; 56: 128-34.

8. Helldén LB, Dérand T, Johansson S, Lindberg A. The CrescoTi Precision method: Description of a simplified method to fabricate titanium superstructures with passive fit to osseointegrated implants. Journal of Prosthetic Dentistry. 1999; 82: 487-491.

9. Longoni S, Matteo S, Fabrizio A, Marco A, Marco B. Passive definitive fit of bar-supported implant overdentures. Implant Dentistry. 2006; 15: 129-134.

10. Mcalarney ME, Stavropoulos DN. Theoretical cantilever lengths versus clinical variables in fifty-five clinical cases. Journal of Prosthetic Dentistry. 2000; 83: 32-43.

11. Taylor TD. Prosthodontic problems and limitations associated with osseointegration. Journal of Prosthetic Dentistry. 1998; 79: 74-78.

12. Uysal H, Kurtoglu C, Gurbuz R, Tutuncu N. Structure and mechanical properties of Cresco-Ti laser-welded joints and stress analyses using finite element models of fixed distal extension and fixed partial prosthetic designs. Journal of Prosthetic Dentistry. 2005; 93: 235-244.

13. Vallittu PK. Dimensional accuracy and stability of polymethyl methacrylate reinforce with metal wire or continuous glass fiber. Journal of Prosthetic Dentistry. 1996; 75: 617-621.

14. Zavanelli AC, Dekon SFC, Zavanelli RA, Mazaro JVQ, Costa PS. Planejamento em prótese parcial fixa: polígono de roy. Revista Odonto Ciência. 2005; 26: 14-19.

15. Alonso FR, Triches DF, Teixeira ER, Hirakata LM. Marginal fit of implant-supported fixed prosthesis frameworks with prefabricated and calcinable cylinders. Revista Odonto Ciência. 2008; 23: 320-324.

16. EI Mekawy N, Khalifa A, Baker ZN, Quan P, Qashout W. The impact of distal cantilever extension on the stress around four implants connected by a bar retained palateless overdenture (in vitro stress analysis). Journal of Oral Hygiene and Health. 2017; 5: 223. 